\title{
Conhecimento de Estudantes de Medicina sobre Suporte Básico de Vida no Atendimento à Parada Cardiorrespiratória
}

\section{Medical Student Knowledge about Basic Life Support in the Attendance of Cardiorespiratory Arrest Care}

\author{
Thalita da Rocha Bastos ${ }^{I}$ (iD \\ Maria Samara Alves da Silva ${ }^{I I}$ (iD \\ Camila Pantoja Azevedo ${ }^{I I I}$ [D \\ Lucas Emannuel dos Santos Bordallo ${ }^{I}(\mathbb{D}$ \\ Ana Cristina Vidigal Soeiro ${ }^{I}$ iD
}

\section{PALAVRAS-CHAVE}

- Reanimação Cardiopulmonar.

- Emergências.

- Parada Cardíaca.

- Educação Médica.
I'Universidade do Estado do Pará, Belém, Pará, Brasil.

${ }^{\mathrm{II}}$ Universidade Federal do Pará, Belém, Pará, Brasil.

${ }^{\mathrm{III}}$ Centro Universitário do Pará, Belém, Pará, Brasil. 


\section{KEYWORDS}

- Cardiopulmonary Resuscitation.

- Emergencies.

- Heart Arrest.

- Medical Education.

Recebido em 27/4/20

Aceito em 11/7/20

\section{INTRODUÇÃO}

A intervenção imediata em situações de emergência é necessária para a redução das possíveis sequelas de um evento traumático e aumento da sobrevida das vítimas. Anualmente, cerca de 60 milhões de pessoas sofrem algum tipo de traumatismo, o que corresponde a uma em cada seis internações hospitalares ${ }^{1}$. Neste contexto, o atendimento pré-hospitalar (APH) é de fundamental importância para a minimização das sequelas ao paciente $^{2}$ o que demanda o preparo adequado das equipes para agir de forma rápida e eficaz.

$\mathrm{O}$ atendimento pré-hospitalar prestado às vítimas compreende desde orientações médicas, até procedimentos de socorro a partir de veículos para suporte básico ou avançado ${ }^{3}$. As medidas de intervenção visam à manutenção da vida por meio da estabilização da vítima e posterior locomoção para o ambiente hospitalar, onde poderá receber atendimento avançado. Dessa maneira, o APH se mostra essencial, uma vez que na maioria dos casos não há tempo para que ocorra a locomoção até o ambiente hospitalar, sem que o paciente já não tenha evoluído a óbito ou adquirido sequelas, caso o atendimento inicial não tenha sido prestado ${ }^{4}$.

Dentre as emergências médicas, a parada cardiorrespiratória (PCR) é definida como cessação ou redução da atividade mecânica do coração, confirmada pela ausência de circulação, sem pulso central detectável, além de apneia ou respiração parcialmente ausente, que culminam em redução do aporte de oxigênio aos tecidos, sendo uma das principais causas de morte no mundo 5 . Há estimativas de que, anualmente, 200 mil pessoas sofram uma PCR no Brasil ${ }^{6}$. Além disso, de acordo com a American Heart Association (AHA), aproximadamente $90 \%$ das vítimas que sofrem de parada cardiorrespiratória fora do hospital evoluem a óbito ${ }^{7,8}$.

O Suporte Básico de Vida (SBV) é definido por um conjunto de estratégias que visam manter o suporte à vítima até a chegada da equipe de emergência, através de ações voltadas à melhora do prognóstico do paciente vítima de PCR em ambiente pré-hospitalar ${ }^{910}$.

Vale ressaltar que o protocolo do SBV engloba diversos aspectos

\section{ABSTRACT}

Introduction: Cardiorespiratory Arrest (CRA) is characterized as an interruption or reduction of mechanical activity of the heart and breath activity. As a result of reduction of oxygen and nutrients for the corporal tissue, there is risk of death, which makes the CRA a severe medical emergency. In this context, the correct performance of basic life support in prehospital treatment is of fundamental importance to diminish the mortality rate and complications in CRA victims. Considering the importance of the topic in medical teaching, the present study was aimed at identifying the knowledge of medical students about the subject, in a way to verify whether the students know how to identify the signals that indicate a cardiorespiratory arrest, the sequence of measure applied during the prehospital care of CRA victims, and the adequate techniques for the medical procedure. Method: The present study adopted an observational, exploratory, descriptive and quantitative approach, with a sample of 245 students of the medicine course at Universidade Estadual do Pará. To collect the samples, one quiz contaning 18 questions was used and applied with Google Forms. Results: The knowledge of the students was included the management of compression techniques; the correct use of the automated external defibrillator (AED) and airway management. Conclusions: Although there was a high amount of hits, the necessity of a better approach on the topic was observed during medical training, to enable the correct prehospital treatment of CRA victims, due to the importance of such procedure in medical emergency. 
dos pesquisadores, contendo 18 questões de múltipla escolha a respeito do protocolo de Suporte Básico de Vida (SBV) e sobre Parada Cardiorrespiratória (PCR). O questionário foi disponibilizado no e-mail dos participantes após anuência da coordenação do curso, com o uso da Plataforma do Google Forms, e mediante aceite do Termo de Consentimento Livre e Esclarecido (TCLE).

As perguntas do questionário foram projetadas para atender aos objetivos da pesquisa e incluíam questões sobre sinais indicativos de parada cardiorrespiratória; sequência de medidas aplicadas durante o atendimento pré-hospitalar; recursos, técnicas e manobras indicadas na realização das intervenções.

Após a coleta, os dados foram agrupados por cada série do curso e armazenados em forma de planilha nos programas Microsoft Excel 2016 e Microsoft Word 2016. Posteriormente, foi realizada a análise pelos programas Bioestat 5.3 e Microsoft Excel 2016.

\section{RESULTADOS}

Do total de 245 estudantes, 70 (28,6\%) eram alunos do primeiro ano, $53(21,6 \%)$ do segundo, $42(17,1 \%)$ do terceiro, 33 (13,5\%) do quarto, 28 $(11,4 \%)$ do quinto e 19 (7.8\%) do sexto ano do curso de medicina.

Quando questionados sobre a vivência em uma situação de parada cardiorrespiratória, $202(82,4 \%)$ alunos responderam negativamente e $43(17,6 \%)$ responderam afirmativamente. Desse total que respondeu positivamente, $20(46,51 \%)$ eram do internato, $14(32,55 \%)$ do ciclo clínico e 9 (20,93\%) do básico.

Em relação ao sinal indicativo de parada cardiorrespiratória, 226 $(92,2 \%)$ alunos responderam corretamente à pergunta. Observou-se que a taxa de erro do primeiro ano foi de $18,58 \%$, e do terceiro ano foi de $7,15 \%$, sendo essas as maiores proporções dos seis anos do curso.

\begin{tabular}{|c|c|c|}
\hline $\begin{array}{r}\text { Tabela } 1 \\
\text { Conhecimentos dos discent }\end{array}$ & s sobre SBV. & \\
\hline & CORRETO & INCORRETO \\
\hline Sinal indicativo de parada cardiorrespiratória & $\begin{array}{c}226 \\
(92,2 \%)\end{array}$ & $\begin{array}{c}19 \\
(7,8 \%)\end{array}$ \\
\hline $\begin{array}{l}\text { Primeira medida a ser implementada no } \\
\text { atendimento pré-hospitalar }\end{array}$ & $\begin{array}{c}216 \\
(88,2 \%)\end{array}$ & $\begin{array}{c}29 \\
(11,8 \%)\end{array}$ \\
\hline Número de telefone a ser acionado & $\begin{array}{c}243 \\
(99,2 \%)\end{array}$ & $\begin{array}{c}2 \\
(0,8 \%)\end{array}$ \\
\hline $\begin{array}{l}\text { Modo de verificação da responsividade do } \\
\text { indivíduo }\end{array}$ & $\begin{array}{c}192 \\
(78,4 \%)\end{array}$ & $\begin{array}{c}53 \\
(21,6 \%)\end{array}$ \\
\hline Medida de pulso indicada & $\begin{array}{c}231 \\
(94,3 \%)\end{array}$ & $\begin{array}{c}14 \\
(5,7 \%)\end{array}$ \\
\hline $\begin{array}{l}\text { Manobra de retificação de vias áreas com } \\
\text { suspeita de trauma cervical e PC }\end{array}$ & $\begin{array}{c}161 \\
(65,7 \%)\end{array}$ & $\begin{array}{c}84 \\
(34,3 \%)\end{array}$ \\
\hline $\begin{array}{l}\text { Ciclo de ventilações/compressões mais } \\
\text { adequado }\end{array}$ & $\begin{array}{c}190 \\
(77,6 \%)\end{array}$ & $\begin{array}{c}55 \\
(22,4 \%)\end{array}$ \\
\hline $\begin{array}{l}\text { Tempo mínimo e máximo para a checagem } \\
\text { do pulso }\end{array}$ & $\begin{array}{c}166 \\
(67,8 \%)\end{array}$ & $\begin{array}{c}79 \\
(32,2 \%)\end{array}$ \\
\hline $\begin{array}{l}\text { Ação diante da chegada do dispositivo } \\
\text { externo automático (DEA) }\end{array}$ & $\begin{array}{c}143 \\
(58,4 \%)\end{array}$ & $\begin{array}{c}102 \\
(41,6 \%)\end{array}$ \\
\hline Correta adequação da ventilação & $\begin{array}{c}218 \\
(89,0 \%)\end{array}$ & $\begin{array}{c}27 \\
(11,0 \%)\end{array}$ \\
\hline $\begin{array}{l}\text { Ritmo simulado dos batimentos cardíacos } \\
\text { durante as compressões }\end{array}$ & $\begin{array}{c}160 \\
(65,3 \%)\end{array}$ & $\begin{array}{c}85 \\
(34,7 \%)\end{array}$ \\
\hline $\begin{array}{l}\text { Profundidade mais adequada das } \\
\text { compressões }\end{array}$ & $\begin{array}{c}151 \\
(61,6 \%)\end{array}$ & $\begin{array}{c}94 \\
(38,4 \%)\end{array}$ \\
\hline
\end{tabular}

Fonte: Protocolo da pesquisa

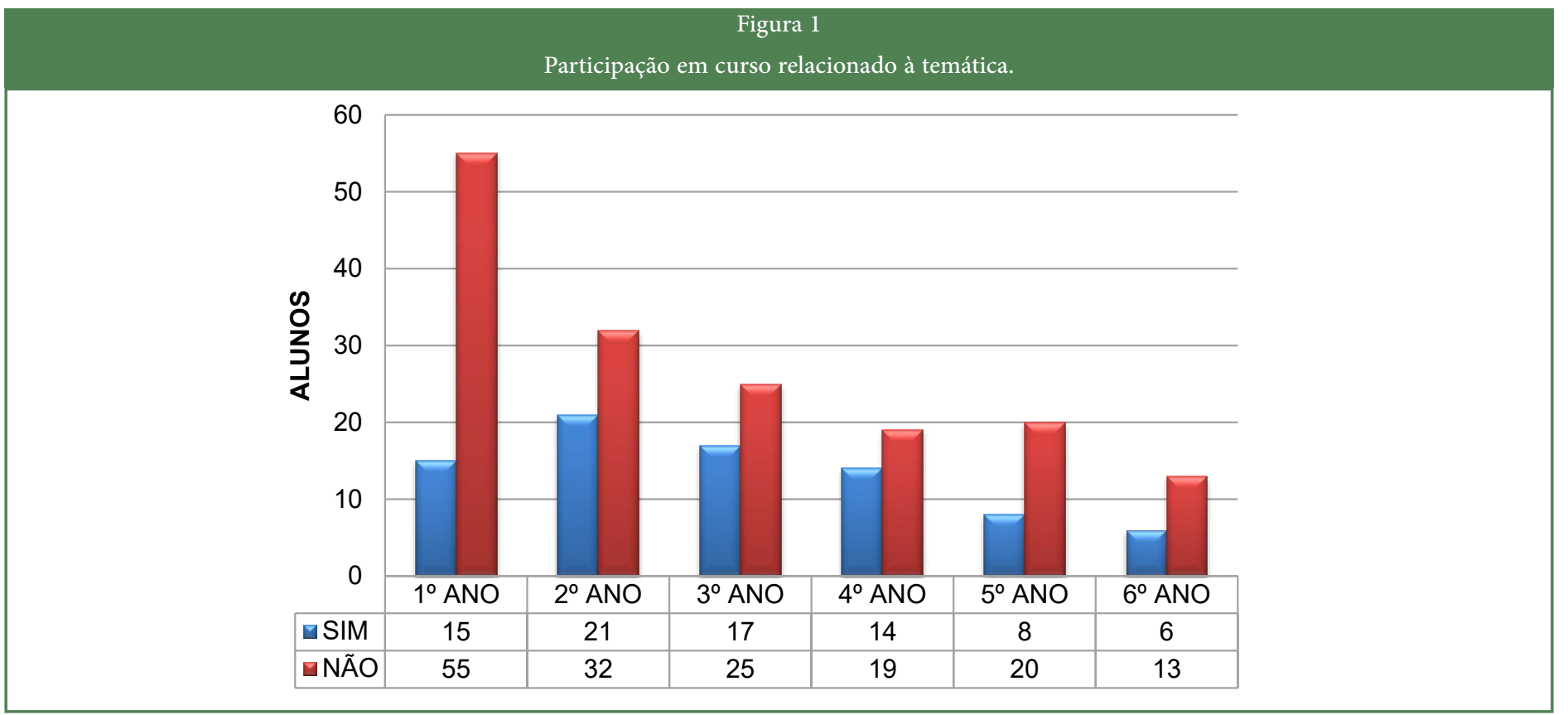

Fonte: Protocolo da pesquisa 


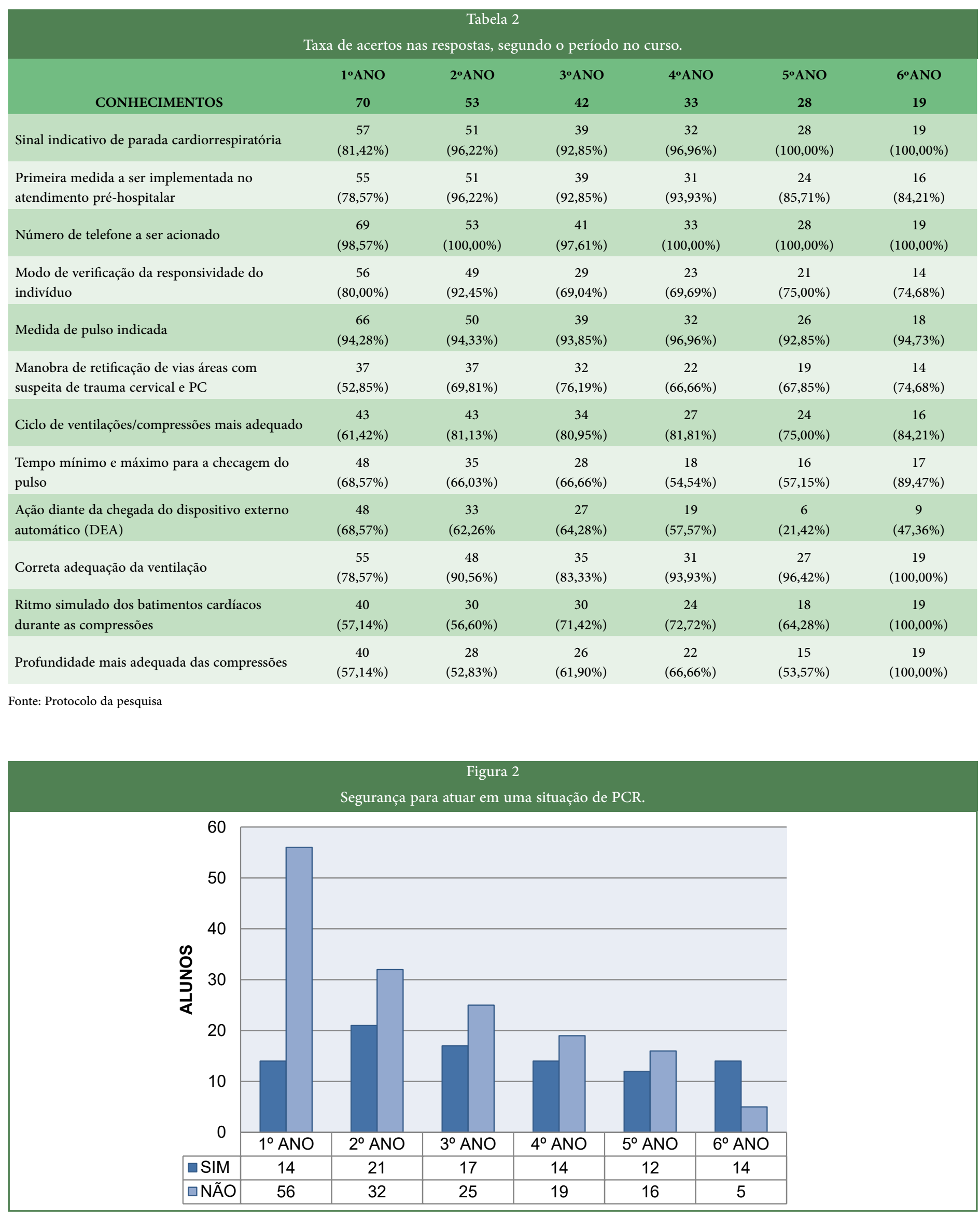

Fonte: Protocolo da pesquisa 
Em relação à pergunta que tratava da primeira medida no atendimento pré-hospitalar diante de uma parada cardiorrespiratória, 216 $(88,2 \%)$ alunos responderam corretamente, mencionando a importância de checar a segurança do local. Vale ressaltar que os índices de acerto foram mais elevados nos três últimos anos do curso.

Quando perguntados sobre a manobra a ser utilizada na retificação de vias aéreas nos pacientes que, além da PCR, têm suspeita de trauma cervical, $161(65,7 \%)$ alunos responderam "Jaw- Thrust". Além disso, em relação ao tempo mínimo e máximo para a checagem do pulso, 166 $(67,8 \%)$ dos acadêmicos apontaram " 5 a 10 segundos".

Quanto à atitude na chegada do dispositivo externo automático (DEA), 143 (58,4\%) participantes responderam corretamente que devem ser interrompidas as compressões para o posicionamento imediato do DEA; 69 (28,2\%) afirmaram que a medida correta seria colocar o DEA e manter as compressões; $29(11,8 \%)$ escolheram a alternativa que afirmava que deveria ser feito primeiramente o término do ciclo para a posterior colocação do DEA e apenas $4(1,6 \%)$ alunos afirmaram a necessidade de colocar o DEA e manter a ventilação.

No que concerne ao ritmo mais adequado para simular os batimentos cardíacos durante as compressões, 160 (65,3\%) alunos marcaram corretamente a opção "100 a 120 compressões por minuto". Ademais, 164 $(66,9 \%)$ alunos afirmaram nunca ter feito nenhum curso extracurricular envolvendo o assunto. Dos $229(93,5)$ alunos que já participaram de simulações de compressão torácica, constatou-se que 151 (61,6\%) deste total não se sentem preparados para atuar frente a uma situação de PCR.

\section{DISCUSSÃO}

A literatura científica é continuamente atualizada quanto à abordagem da parada cardiorrespiratória; entretanto, pesquisas sugerem que, apesar dos estudos disponíveis, as habilidades e o nível de informação sobre a detecção da PCR, sequência do suporte básico de vida e manobras a serem realizadas, ainda são insuficientes na implementação das intervenções ${ }^{17}$. Em razão dessa realidade, pesquisadores têm defendido a importância de ações educativas que permitam aos profissionais uma sólida fundamentação teórica, com atualização contínua sobre as diretrizes a serem adotadas. Nesse cenário, também estão incluídos os treinamentos a serem ofertados aos estudantes de medicina, antes mesmo de terminarem o ciclo clínico. Esse esforço visa melhorar o atendimento às vítimas de PCR e aumentar sua sobrevida ${ }^{18}$.

No curso de medicina onde a coleta de dados foi realizada, o ensino de conteúdos relacionados à ressuscitação cardiopulmonar (RCP) é iniciado no segundo semestre, durante o módulo de Habilidades Profissionais (HP), com uso de metodologias ativas de aprendizagem. Nesta ocasião, os alunos são submetidos a um treinamento prático com foco no Suporte Básico de Vida (SBV), no qual são utilizados manequins não vivos. Os conteúdos são novamente abordados de forma mais sistemática no oitavo semestre, tanto em HP quanto nas sessões tutoriais, agora com ênfase no Suporte Avançado de Vida (SAV).

É importante destacar que, de acordo com as orientações do American College of Emergency Physicians, o contato precoce com o protocolo do SBV, bem como a possibilidade de treinamento prático das compressões torácicas por estudantes da área da saúde, determina um melhor desempenho frente ao cenário de uma parada cardiorrespiratória ${ }^{19}$. Os achados da presente pesquisa corroboram a importância das experiências práticas no aprendizado de tais conteúdos, o que possivelmente favorece de forma positiva a incorporação e a retenção das informações.

A PCR é um evento frequente na prática clínica e no cotidiano médico; entretanto, a maior parte dos participantes da pesquisa nunca presenciou esse acontecimento. Trata-se de um fator importante a ser destacado, tendo em vista que logo estarão desenvolvendo suas atividades como futuros médicos. Em relação aos alunos do primeiro ao sexto ano, há elevação na porcentagem de estudantes que já presenciaram uma PCR de acordo com a progressão no curso, o que pode estar associado às atividades de articulação ensino-serviço - estratégia característica nos cursos que adotam metodologias ativas ${ }^{20}$.

O reconhecimento adequado de PCR é indispensável na definição das medidas terapêuticas a serem realizadas, haja vista que existem outras condições que também podem ocasionar perda de consciência. De acordo com o Advanced Cardiovascular Life Support (ACLS), a ausência de pulso e de movimentos respiratórios caracteriza adequadamente a $\mathrm{PCR}^{21}$, sendo que a maior parte dos discentes mostrou-se apta à identificação desses sinais. Cabe ressaltar, entretanto, que tais achados divergem de outras pesquisas com a mesma temática, as quais demonstram limitações nesse conhecimento, por parte de discentes e também de profissionais da área de saúde ${ }^{22}$.

O Serviço Móvel de Urgência (SAMU) é o principal órgão responsável pelo atendimento de pacientes em ambiente pré-hospitalar, incluindo a PCR, e seu acionamento, por meio do número 192, deve ocorrer de forma precoce ${ }^{23}$. O percentual de discentes que conheciam o fluxo de funcionamento do SAMU foi satisfatório e representa uma informação fundamental para melhorar a eficácia das intervenções, haja vista que os serviços de transporte têm papel importante em emergências médicas dessa natureza ${ }^{24}$.

A garantia da segurança do local é indispensável para a integridade da vítima e do socorrista em ambiente pré-hospitalar e deve ser priorizada antes do início dos procedimentos. Os achados da pesquisa revelaram que há um grau satisfatório de conhecimento acerca dessa orientação, estando as respostas dos alunos condizentes com o descrito como sequência de atendimento adequada nos protocolos da American Heart Association $(\mathrm{AHA})^{11}$. Vale destacar que esse conhecimento é importante para a redução de riscos desnecessários durante o atendimento pré-hospitalar.

A perda súbita de consciência é uma das principais características que levam à suspeita de uma PCR, mas é muito importante ressaltar que outras patologias podem apresentar esse quadro, a exemplo da hipoglicemia ${ }^{25}$. Muitos pacientes, no momento da checagem da responsividade, podem demonstrar alguma resposta, como movimentos musculares ou abertura ocular, devendo-se, nesse caso, descartar a hipótese de PCR e evitar compressões torácicas desnecessárias. Essa habilidade foi demonstrada por um percentual satisfatório de participantes da pesquisa.

O conhecimento sobre as manobras de retificação das vias aéreas foi a área na qual se observou uma das maiores discrepâncias em relação à resposta correta, sendo que $34,3 \%$ dos alunos não identificaram corretamente qual a maneira de se obter a perviedade da via aérea em suspeita de lesão cervical. De certa forma, o resultado é preocupante, haja vista que a estabilidade da coluna cervical do paciente deve ser uma das principais preocupações do socorrista, visando diminuir possíveis sequelas no pós-PCR, sendo muitas vezes negligenciada pelos profissionais ${ }^{26}$. Do mesmo modo, um estudo realizado na Índia, que contou com a participação de 42 alunos de medicina, também relatou um baixo nível

REVISTA BRASILEIRA DE EDUCAÇÃO MÉDICA

5 44 (4) : e111; 2020 
de conhecimento sobre as manobras de retificação, com apenas 5 alunos sabendo realizar as manobras ${ }^{27}$.

O início imediato do protocolo do SBV é importante para que se obtenha a minimização das sequelas. Dessa forma, o tempo ideal gasto para a confirmação da ausência de pulso é um conhecimento de fundamental importância em uma abordagem emergencial e pré-hospitalar, pois quanto mais rápido e eficiente for o atendimento, melhor o desfecho clínico $^{28}$. O estudo demonstrou que cerca de um terço dos alunos não sabe identificar o tempo correto de checagem do pulso. Entretanto, mais de $90 \%$ soube identificar o pulso carotídeo como o mais indicado para avaliação da PCR, resultado semelhante ao encontrado em um estudo feito com alunos de uma universidade do Rio de Janeiro, em que o índice de acertos quanto a essa habilidade foi satisfatório ${ }^{28}$.

O fornecimento de um fluxo adequado de compressões e ventilação é de suma importância na manutenção da oxigenação tecidual, principalmente do coração e cérebro, visando diminuir as chances de sequela $^{11}$. Nesse aspecto, foram identificadas lacunas no conhecimento em relação à técnica de 5 ciclos de 2 ventilações a cada 30 compressões. De maneira oposta, um estudo observacional realizado com leigos, no qual foi usado manequins não vivos no treinamento, mostrou resultados positivos no processo de ressuscitação, tendo em vista que um número significativo de participantes se mostrou apto a realizar a frequência correta de compressões/ventilações ${ }^{29}$.

Quanto à chegada do DEA, uma parcela significativa dos estudantes não soube responder adequadamente e de acordo com o protocolo da AHA, o que deve ser feito. Observou-se que o maior número de acertos ocorreu nos primeiros anos, ao contrário do esperado, uma vez que os alunos de semestres mais avançados deveriam demonstrar maior conhecimento teórico e prático sobre o assunto.

O elevado número de estudantes que respondeu à pergunta incorretamente corrobora os achados de um estudo realizado com profissionais da área de enfermagem, o qual constatou insuficiência no conhecimento quanto ao uso do DEA, aparelho que deve ser utilizado de imediato para a análise do ritmo cardíaco e desfibrilação precoce. A utilização do aparelho aumenta a taxa de sobrevida, mas, nesse caso, o dispositivo deverá ser usado em até 5 minutos após a parada cardiorrespiratória $^{30,31}$.

Quando questionados acerca de como realizar ventilações eficientes, um número significativo dos alunos respondeu corretamente, com aumento dos acertos nas séries mais avançadas. Vale destacar a importância da alta taxa de acerto quanto a essa etapa da RCP, uma vez que reconhecer a elevação do tórax como indicativo de ventilações eficientes é útil para que, quando ausente, o socorrista saiba que deve fazer a reavaliação da técnica, visando garantir insuflação eficaz. Além disso, dados da literatura ressaltam a importância de se evitarem ventilações rápidas e forçadas, com o intervalo de tempo ideal entre elas sendo de até 5 segundos, no máximo ${ }^{32}$.

Durante a parada cardiorrespiratória, a compressão cardíaca e a ventilação objetivam garantir a permanência do fluxo sanguíneo ao cérebro e ao miocárdio. Dessa forma, de acordo com recomendações da AHA, o ritmo mais adequado para a prevenção de danos é de 100 a 120 compressões por minuto, e a profundidade das compressões, de 5 a 6 $\mathrm{cm}^{11}$. De outro modo, estudos também demonstram que compressões bem-sucedidas garantem melhor resposta cardíaca após o uso do $\mathrm{DEA}^{28}$.

De maneira semelhante ao encontrado na literatura, os resultados indicam conhecimento insatisfatório quanto ao ritmo e à profundidade adequada das compressões, o que prejudica a qualidade do atendimento pré-hospitalar prestado à vítima ${ }^{33,34}$. Em relação a essas duas variáveis, não foi possível observar aumento do conhecimento nos anos mais avançados do curso, quando comparados aos anteriores.

Uma das formas para melhorar a agregação de conhecimentos sobre SBV é a realização de cursos e treinamentos na área. Nesse aspecto, Baldi et al. (2019) ressaltam que uma das possíveis justificativas para o conhecimento insuficiente de alguns estudantes e profissionais da saúde é a limitada oferta de atividades acadêmicas voltadas ao conhecimento prático e teórico sobre o suporte básico de vida, ao longo da sua formação ${ }^{35}$. Dessa forma, é necessário estimular a maior oferta de conteúdos curriculares dessa natureza para os alunos da instituição, visto que uma parcela significativa ainda não teve contato com nenhum tipo de atividade acadêmica voltada a essa finalidade.

Além disso, mais da metade dos participantes afirmaram não se sentir seguros/preparados para intervenções dessa natureza, com destaque para o elevado número de alunos do internato que responderam negativamente ao questionamento. Esse resultado está de acordo com o encontrado em um estudo realizado com alunos de medicina da Faculdade Federal de Sergipe, no qual foi constatado que $72,43 \%$ dos alunos não consideravam seus conhecimentos suficientes para atuar frente a uma $\mathrm{PCR}^{19}$. Tais achados precisam ser problematizados, considerando que, para um atendimento de qualidade às vítimas, é esperado que os profissionais da saúde estejam confiantes e capacitados para realizar as intervenções, um objetivo que precisa ser incentivado desde o começo da graduação ${ }^{36}$.

Os achados evidenciam a necessidade de intensificar as aulas práticas e treinamentos, a fim de que os acadêmicos se sintam mais confiantes para realizar o Suporte Básico de Vida, uma vez que inúmeras pesquisas relatam que aqueles que foram treinados para atuar frente à PCR e não têm um contato contínuo com a prática do protocolo acabam tendo mais dificuldade para reter o aprendizado de tais conteúdos ${ }^{37}$.

A formação dos profissionais deve priorizar o desenvolvimento de habilidades teórico-práticas, mas deve estar articulada com a realidade. Porém, ainda que tais conteúdos sejam parte da rotina de muitos cenários de atendimento, o número reduzido de experiências e simulações acarreta lacunas no acesso a informações e no aprendizado de procedimentos que deveriam ser priorizados como parte importante da educação médica ${ }^{38}$.

\section{CONCLUSÕES}

Os resultados da pesquisa demonstraram que o ensino do suporte básico de vida no início da graduação contribui positivamente para o conhecimento dos alunos sobre o protocolo, o que manteve satisfatória a porcentagem de acertos na maioria das questões, mesmo que só $17,6 \%$ dos participantes já tenham presenciado uma parada cardiorrespiratória. É importante destacar que mais de $90 \%$ dos alunos sabe assinalar os sinais indicativos de PCR e o contato do serviço que deve ser imediatamente acionado, o SAMU, e mais de $80 \%$ reconhecem a sequência correta de atendimento, a se iniciar pela garantia da segurança do local. Os principais déficits de conhecimento se encontram na técnica correta de compressão, com percentual de erro acima de $35 \%$ dos participantes quanto à profundidade e ao ritmo que devem ser realizados. Além disso, menos de $60 \%$ dos participantes reconhece o posicionamento do DEA como prioridade durante a chegada do serviço de atendimento, prejudicando 
o prognóstico do paciente. Outra relevante falha está relacionada à utilização das manobras de retificação de via aérea, com mais de 35\% não sabendo indicar qual a técnica mais adequada em casos de trauma cervical. Quando comparados os conhecimentos dos alunos em relação ao ano em que estão regularmente matriculados, observou-se que há um aumento na quantidade de acertos de alunos em semestres mais avançados em comparação aos alunos de semestres iniciais, o que pode estar relacionado à intensificação das atividades práticas e à revisão do protocolo no semestre pré-internato. Mesmo com uma média de acertos sempre acima de 50\%, é importante ressaltar que há importantes lacunas no ensino médico que precisam ser avaliadas e enfrentadas. Considerando a importância do SBV, pretende-se que os achados do presente estudo possam estimular o maior debate sobre o tema, contribuindo para a formação de futuros profissionais e, assim, potencializando ações mais eficazes no suporte às vítimas de PCR.

\section{REFERÊNCIAS BIBLIOGRÁFICAS}

1. Maia ER, Gonçalves Júnior J, Lima EP, Campos W, Jovino EM, Fernandes FF, et al. Conhecimentos em Atenção Pré-Hospitalar e Suporte Básico de Vida por Estudantes Recém-ingressos de Medicina. Rev Bras Educ Med. 2014;38(1):59-64.

2. Morais DA. Ressuscitação cardiopulmonar pré-hospitalar: fatores determinantes da sobrevida. Belo Horizonte, MG. 2012. Doutorado [Tese] - Universidade Federal de Minas Gerais.

3. Brasil. Ministério da Saúde. Secretária de Atenção à Saúde. Protocolos de Intervenção para o SAMU 192 - Serviço de Atendimento Móvel de Urgência. Brasília: Ministério da Saúde, 2014.

4. Silva AA, Menechini BR, Nunes CR, Andrade CCF. Atuação do enfermeiro no atendimento pré-hospitalar em parada cardiorrespiratória. Revista científica interdisciplinar. 2017;2(1):54-64.

5. Silva RMFL, Silva BAGL, Silva FJM, Amaral CFS. Ressuscitação cardiopulmonar de adultos com parada cardíaca intra-hospitalar utilizando o estilo Utstein. Rev Bras Ter Intensiva. 2016;28(4):427-435.

6. Bravin R, Sobrinho A, Seixas M. A importância do Suporte Básico de Vida na Odontologia. RFO UPE. 2018;23(3):371-6.

7. Ruão MBAB. Emergência Médica Pré-Hospitalar - Quando os segundos são vidas. Porto; 2018. Mestrado [Dissertação] Universidade do Porto.

8. Pergola AM, Araujo IEM. O leigo e o suporte básico de vida. Ver Esc Enferm USP. 2009;42(2):335-342.

9. Brasil. Ministério da Saúde. Secretária de Atenção à Saúde. Protocolos de Intervenção para o SAMU 192 - Serviço de Atendimento Móvel de Urgência. Brasília: Ministério da Saúde, 2016.

10. Alves CA, Barbosa CNS, Faria HTG. Parada Cardiorrespiratória e Enfermagem: o Conhecimento a Cerca do Suporte Básico de Vida. Cogitare Enferm. 2013;18(2):296-301.

11. American Heart Association. Guidelines for Cardiopulmonary Resuscitation and Emergency Cardiovascular Care. Destaques da Atualização das Diretrizes da American Heart Association 2015 para RCP e ACE. Texas (EUA); 2015. [capturado 20 mar. 2020]. Disponível em: https://eccguidelines.heart.org/wp-content/ uploads/2015/10/2015-AHA-Guidelines-Highlights-Portuguese.pdf.

12. Luchtemberg $\mathrm{MN}$, Pires DEP. Enfermeiros do Serviço de Atendimento Móvel de Urgência: perfil e atividades desenvolvidas.
Rev Bras Enferm. 2016;69(2):213-220.

13. Luciano PM, Matsuno AK, Moreira RSL, Schmidt A, Pazin FA. Suporte básico de vida. Ver Soc Cardiol Estado de São Paulo. 2010;20(2):230-238.

14. Carneiro LLNB, Baldoino LS, Virgineo MS. Nível de conhecimento dos enfermeiros sobre as técnicas de reanimação cardiopulmonar. Revista Interdisciplinar. 2018;11(3):22-35.

15. Granja C, Nassar Junior AP. Desfecho neurológico após parada cardíaca: problemas frios e sombrios. Rev Bras Ter Intensiva. 2015;27(4):305-306.

16. Sá LBMA, Santos DL, Lopes EB, Vasconcelos MS, Leite LAR. A atuação do fisioterapeuta no time de resposta rápida em um hospital de alta e média complexidade na Amazônia. Fisioterapia Brasil. 2019;20(2):179-184.

17. Santos JRD. A abordagem da equipe de enfermagem do protocolo de parada cardiorrespiratória na unidade básica de saúde. Revista Recien. 2018;8(22):34-41.

18. Santos MS, Toledo LV, Alves KR, Santana MMR, Ribeiro L, Diaz FBBS. Conhecimento da equipe de enfermagem do setor de hemodiálise sobre o atendimento a parada cardiorrespiratória. HU Revista. 2019;43(4):375-381.

19. Roldão ACCM, Oliveira FM. Percepção do conhecimento sobre parada cardiorrespiratória dos graduandos em medicina de uma universidade pública com metodologia ativa de ensino. Lagarto, SE; 2018. Graduação [Trabalho de Conclusão de Curso] - Universidade Federal de Sergipe.

20. Cruz LL, Rego MG, Lima EC. O enfermeiro frente à parada cardiorrespiratória em ambiente hospitalar: desafios do cotidiano. Brasília, DF; 2018. Graduação [Trabalho de Conclusão de Curso] Centro Universitário do Planalto Central Aparecido dos Santos.

21. Disque K. Advanced Cardiac Life Support. Estados Unidos: Satori Continuum; 2016.

22. Santos ACN, Petto J, Barbosa RM, Moura RF, Santos GN, Ladeia AMT. Knowledge of academics and health professionals on Basic Life Support. ABCS Health Sciences. 2020;45:1-9.

23. Sampaio JAMA, Braga TRO, Silva ML, Quental OB. A importância do atendimento pré-hospitalar para o paciente politraumatizado no Brasil: Uma Revisão Integrativa. Id on Line Rev. Mult. Psic. [online]. 2019;13(48):889-903. [capturado 11 abr. 2020]; Disponível em: https://idonline.emnuvens.com.br/id/article/view/2297/3499.

24. Duong HV, Herrera LN, Moore JX, Donnelly J, Jacobson KE, Carlson JN, et al. National Characteristics of Emergency Medical Services Responses for Older Adults in the United States. Prehosp Emerg Care. 2018;22(1):7-14.

25. Alkhatatbeh MJ, Abdalqader NA, Alqudah MAY. Impaired awareness of hypoglycemia in children and adolescents with type 1 diabetes mellitus in north of Jordan. BMC Endocrine Disorders. 2019;19(1):1-7.

26. Nascimento UA, Silva MAF. Conhecimento do enfermeiro na parada cardiorrespiratória (PCR), em uma unidade de urgência e emergência em Porto Velho/RO. Porto Velho, RO; 2018. Graduação [Trabalho de Conclusão de Curso] - Centro Universitário São Lucas.

27. Pande S, Pande S, Parate V, Pande S, Sukhsohale N. Evaluation of retention of knowledge and skills imparted to first-year medical

\begin{tabular}{l|l}
7 & REVISTA BRASILEIRA DE EDUCAÇÃ̃ MÉDICA \\
\hline $44(4):$ e $111 ; 2020$
\end{tabular} 
students through basic life support training. Adv Physiol Educ. 2014;38(1):42-5.

28. Marques SC, Dias DF, Aragão IPB. Prevalência do conhecimento e aplicação das técnicas de Ressuscitação Cardiopulmonar. Revista Fluminense de Extensão Universitária. 2019;9(1):2-8.

29. Rossler B, Goschin J, Maleczek M, Piringer F, Thell R, Mittlbock M, et al. Providing the best chest compression quality: Standard CPR versus chest compressions only in a bystander resuscitation model. Plos One. 2020;15(2):1-12.

30. Lira TBD, Silva RKD, Soares ARG. Parada cardiorrespiratória e reanimação cardiopulmonar: conhecimento teórico dos enfermeiros da atenção básica. Braz. J Of Develop. 2019;5(10):18682-18694.

31. Ghanem E, Elgazar M, Oweda K, Tarek H, Assaf F, El-Husseny MWA, et al. Awareness of Basic Life Support among Egyptian Medical Students; a Cross-Sectional Study. Emergency. 2018;6(1):1-5.

32. Beesems SG, Wijmans L, Tijssen JGP, Koster RW. Duration of Ventilations During Cardiopulmonary Resuscitation by Lay Rescuers and First Responders Relationship Between Delivering Chest Compressions and Outcomes. Circulation. 2013:127(15):1585-1590.

33. Willmore RD, Veljanoski D, Ozdes F, Stephens B, Mooney J, Crumley SG, et al. Do medical students studying in the United Kingdom have an adequate factual knowledge of basic life support?. World Journal of Emergency Medicine. 2019;10(2):75-80.

34. Korber MI, Kohler T, Weiss V, Pfister R, Michels G. Quality of Basic Life Support - A Comparison between Medical Students and Paramedics. Journal of Clinical and Diagnostic Research. 2016;10(7):33-7.

35. Baldi E, Contri E, Bailoni A, Rendic K, Turcan V, Donchev N, et al. Final-year medical students' knowledge of cardiac arrest and CPR: We must do more!. Int. J Cardiol. 2019;296:76-80.

36. Saquib SA, Al-Harthi HM, Khoshhal AA, Shaher AA, Al-Shammari AB, Khan A, et al. Knowledge and Attitude about Basic Life Support and Emergency Medical Services amongst Healthcare Interns in
University Hospitals: A Cross-Sectional Study. Emergency Medicine International. 2019;2019:1-8.

37. Suárez MG, Martínez CM, Isasi SM, Salgado JG, García DF. Basic Life Support Training Methods for Health Science Students: A Systematic Review. Int J Environ Res Public Health. 2019;16(5):1-15.

38. Fernandes CR, Falcão SNRS, Gomes JMA, Colares FB, Maior MMMS, Correa RV, et al. Ensino de emergências na graduação com participação ativa do estudante. Rev Bras Educ Med. 2014;38(2):261-8.

\section{CONTRIBUIÇÃO DOS AUTORES}

Thalita da Rocha Bastos foi responsável pela organização e desenvolvimento da pesquisa desde a idealização do tema, elaboração do projeto, coleta e análise dos dados, redação e revisão final do artigo. Maria Samara Alves da Silva participou desde a idealização do tema, elaboração do projeto, coleta e análise de dados, formulação, formatação e revisão final do artigo. Camila Pantoja Azevedo participou como pesquisadora desde a revisão de literatura, formulação do questionário, redação, formatação e revisão final do artigo. Lucas Emannuel dos Santos Bordallo participou desde a idealização do tema, construção do projeto, tabulação de dados, redação e revisão do artigo. Ana Cristina Vidigal Soeiro participou como pesquisadora e orientadora em todas as etapas do estudo, incluindo a redação e a revisão final do manuscrito.

\section{CONFLITO DE INTERESSES}

Não houve conflito de interesses em nenhuma etapa da construção do artigo.

\section{ENDEREÇO PARA CORRESPONDÊNCIA}

Thalita da Rocha Bastos. Passagem São Pedro, 43. Residencial Castanheira Q1C4, Atalaia, Ananindeua, PA, Brasil. CEP: 67013-490.

E-mail: thalitarocha08@hotmail.com 